\title{
EVALUACION DEL PROCESO DE AUDITORÍA DE INCAPACIDADES TEMPORALES EN EL PROYECTO DE COLPENSIONES
}

Bogotá, Junio de 2016

Diana Milena Montenegro Rojas

Código: 2193942

\author{
Asesor de trabajo \\ Magnolia del Pilar Ballesteros Cabrera \\ PhD en Salud Pública
}

Universidad Santo Tomás, Bogotá

Especialización en Auditoria de salud

Facultad de Economía

2016 


\section{EVALUACION DEL PROCESO DE AUDITORÍA DE INCAPACIDADES TEMPORALES EN EL PROYECTO DE COLPENSIONES.}

Bogotá, Junio de 2016

Diana Milena Montenegro Rojas

Código: 2193942

Monografía para optar al título de Especialista en Auditoria de salud Asesor de trabajo

Magnolia del Pilar Ballesteros Cabrera

PhD en Salud Pública

Universidad Santo Tomás, Bogotá

Especialización en Auditoria de salud

Facultad de Economía

2016 


\section{ÍNDICE}

\section{Contenido}

RESUMEN

DESCRIPCIÓN DEL PROBLEMA

OBJETIVOS

Objetivo General..................................................................... 11

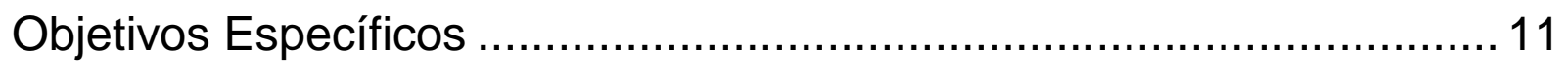

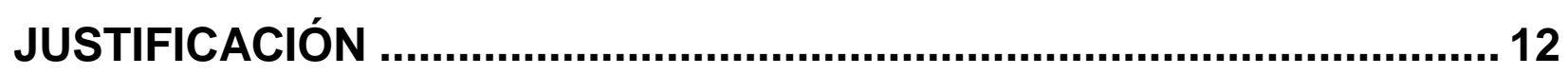

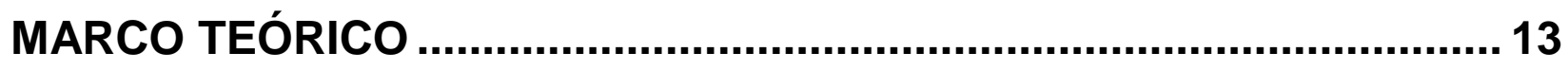

PROCESO DE AUDITORÍA DE INCAPACIDADES TEMPORALES ....... 23

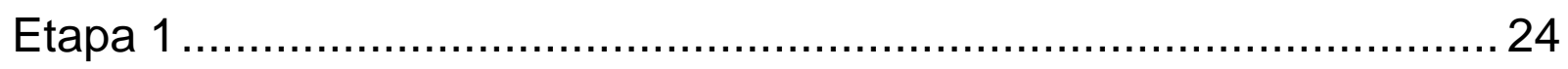

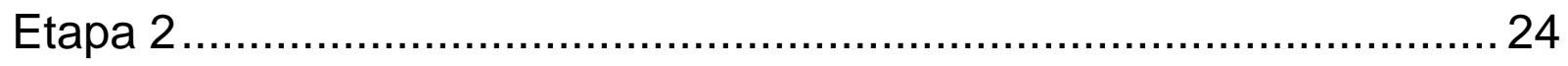

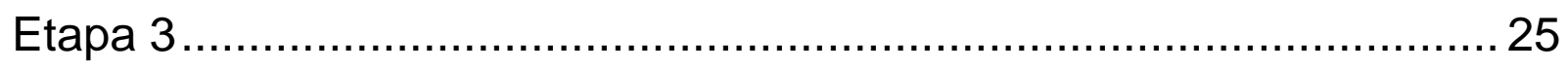

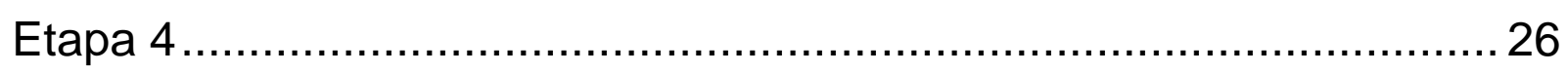

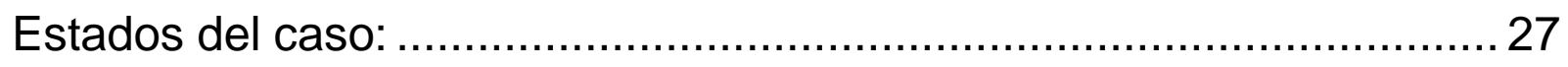

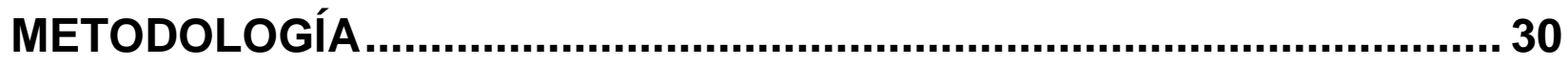

POBLACIÓN Y MUESTRA:

RECOLECCIÓN DE DATOS Y ANALISIS DE INFORMACIÓN:..............30

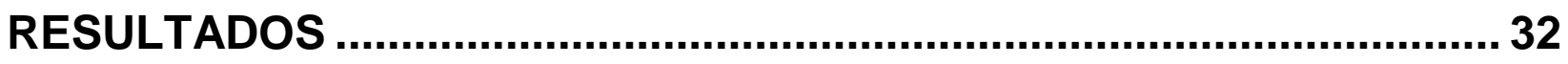

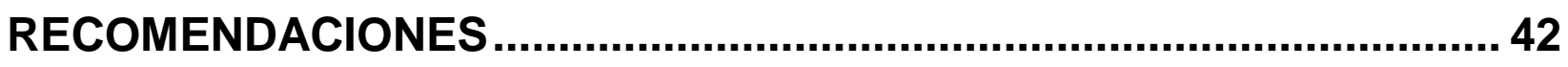

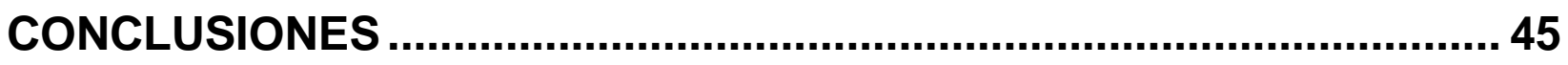

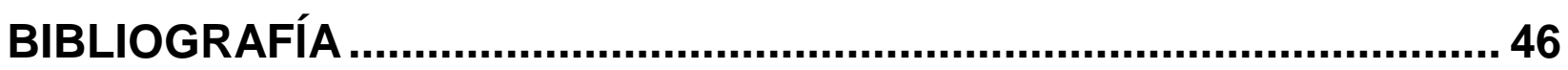

ANEXOS

Anexo 1: Formato De Entrega De Documentos (FED) ......................... 49 


\section{INDICE DE IMÁGENES Y TABLAS}

Contenido

Flujograma.

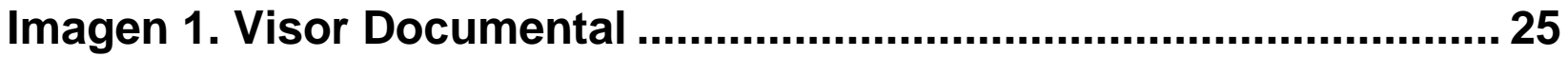

Imagen 2. Hoja De Ruta Incapacidades............................................... 26

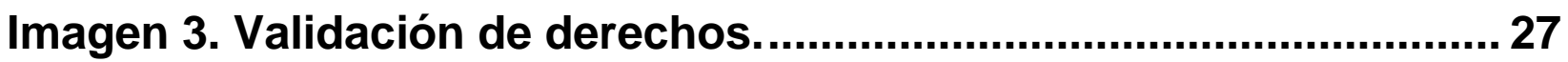

Tabla 1. Formato de medición de tiempos........................................... 31

Tabla 2. Informe a corte de 2 mayo de 2016 ........................................ 33

Tabla 3. Informe a corte de 7 mayo de 2016........................................... 34

Tabla 4. Informe a corte de 11 mayo de 2016 ...................................... 35

Tabla 5. Informe a corte de 25 mayo de 2016 ........................................ 36

Tabla 6. Informe a corte de 30 mayo de 201 ........................................ 37

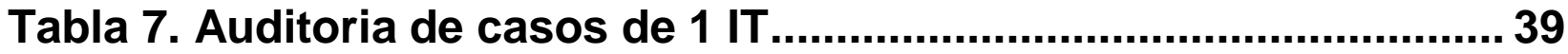

Tabla 8. Auditoria de casos de 3 IT..................................................... 40

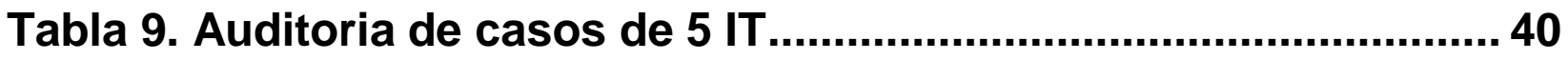

Tabla 10. Auditoria de casos de 10 IT................................................... 40

Tabla 11. Auditoria de casos de 24 IT ....................................................... 41 


\section{RESUMEN}

El principal objetivo de este trabajo ha sido la evaluación del proceso de auditoría de incapacidades temporales en el proyecto de Colpensiones con la organización de ASALUD LTDA, empresa privada dedicada al manejo del área de medicina laboral.

Partiendo de la observación se toman los tiempos y movimientos del auditor de incapacidades temporales (IT) lo cual muestra la oportunidad de gestión en la resolución y liquidación a los afiliados, deja un aporte a la organización de las pautas a mejorar durante el desarrollo del proceso y fortalece los conocimientos aplicados durante la

La evaluación integral del proceso contribuye a la conciencia de crear planes de mejora continua y la actualización dinámica a los mismos, lo que se puede evidenciar por medio del análisis de los resultados, los cuales muestran que si el proceso de auditoría de incapacidades temporales estuviera estructurado y fundamentado en criterios básicos, los auditores tendrían la posibilidad de mejorar la oportunidad en tiempo y criterio al momento de desarrollar el proceso, además que el tener constantemente capacitaciones en el área de medicina laboral

\section{Palabras: evaluación, proceso, oportunidad}




\section{DESCRIPCIÓN DEL PROBLEMA}

ASALUD Ltda. Es una empresa cuyo enfoque consiste en realizar el asesoramiento y manejo de la medicina laboral y la contratación con organizaciones que requieran este servicio (10), en este momento manejan dos proyectos importantes a nivel nacional con la ARL Positiva y AFP COLPENSIONES.

Durante la realización de la auditoría de incapacidades es importante conocer el proceso de inicio desde que ingresa un caso o paquete a las oficinas principales como los puntos de atención de Colpensiones (PAC), y las sedes de Asalud Ltda (ver diagrama 1), la radicación la realiza cada usuario, los documentos los recibe el personal auxiliar quienes se encargan de crear la cita en el aplicativo SAMI, los casos son enviados a la sede principal de Asalud desde las ciudades de recepción, donde se escanea, se sube al aplicativo de manera ordenada y pertinente, para que los jefe auditores de enfermería puedan iniciar la labor de verificación de requisitos y el cumplimiento de los parámetros que se tienen en cuenta al momento de hacer el proceso, los documentos solicitados son: el formato de entrega de documentos, el cual es proporcionado por Asalud, documento de identidad, el certificado de record de incapacidades, las incapacidades, el certificado de rehabilitación y la certificación bancaria, cada uno de estos documentos debe cumplir con unos parámetros para que cada caso se le asigne un estado de gestión donde se da inicio a procesos definidos para cada uno de ellos.

Las falencias percibidas en la auditoria de incapacidades han generado algunos reprocesos como, el tiempo que se demora en llegar un caso de las sedes o los PAC es alrededor de 5 días, por tal razón al prolongar este tiempo los casos que se gestionan en una oportunidad tan extensa se tienden a convertir en una PQR o ligados a procesos jurídicos, la falta de recurso humano en el área de escaneo ya que solo se cuenta con dos personas que realizan esta actividad y son 12 jefes de enfermería los que auditan más de 35 casos diarios, la oportunidad de los casos en validación de derechos está en un promedio de 5 días y ese depende directamente de colpensiones, la inducción al 
personal nuevo es deficiente y desactualizada, por ende los errores cometidos son demasiados y las devoluciones se incrementan en gran cantidad.

De esta manera es importante resaltar que el proceso sufre demoras y falencias las cuales se podrían subsanar, es así como surge la siguiente pregunta:

¿La evaluación del proceso en auditoría de incapacidades temporales, permite mejorar la gestión oportuna para la liquidación de las mismas con relación a los tiempos en que se gestiona cada caso durante el periodo de mayo del 2016 ? 


\section{FLUJOGRAMA}

\section{Diagrama 1}

PROCESO DE AUDITORIA INCAPACIDADES TEMPORALES

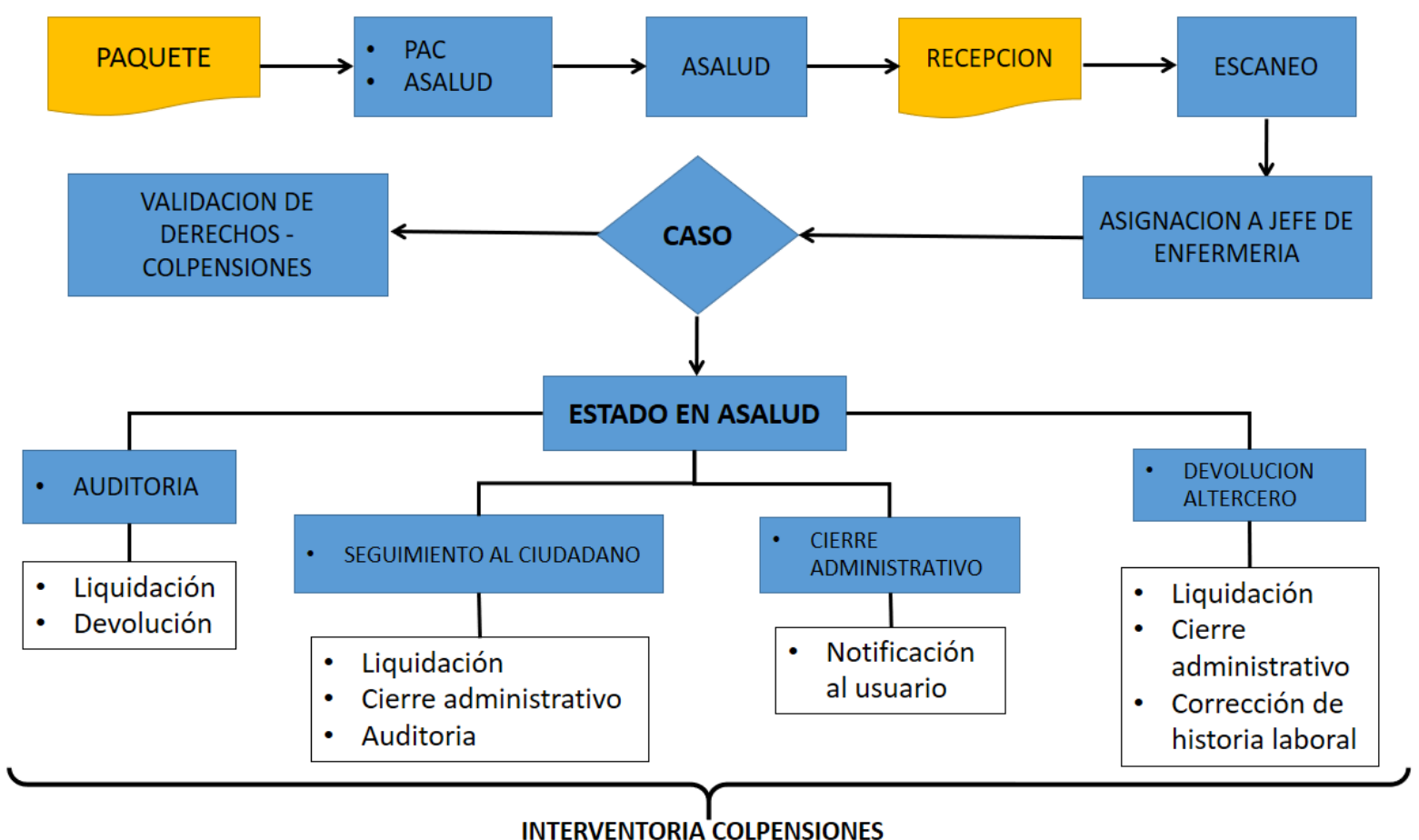

Autor: DIANA MONTENEGRO ROJAS 


\section{OBJETIVOS}

\section{Objetivo General}

- Evaluar el proceso de auditoría de incapacidades temporales en el proyecto de COLPENSIONES con ASALUD LTDA durante el mes de mayo del 2016.

\section{Objetivos Específicos}

- Establecer tiempos y movimientos de los casos que se gestionan en ASALUD LTDA durante el proceso de auditoria en incapacidades a los profesionales encargados.

- Sugerir un plan de mejoramiento que se pueda ver reflejado en la disminución de los requerimientos jurídicos y promueva la gestión oportuna en la liquidación a los usuarios de los casos radicados. 


\section{JUSTIFICACIÓN}

Para la organización es importante tener una mirada objetiva y diferente desde el interior del proceso de auditoría de incapacidades, este trabajo da la oportunidad de tener una experiencia muy enriquecedora, la cual permite conocer el proceso a manera detallada en cada una de las etapas de desarrollo, dejando ver sus fortalezas y debilidades; esto hace que sea más fácil tener una perspectiva detallada de las posibles mejoras $u$ actualizaciones que se quieran realizar.

Realizar una evaluación del proceso de auditoría de incapacidades temporales en el proyecto Colpensiones, es una herramienta de aplicación que aporta a la formación académica como especialista, la experiencia de poner a en práctica los conocimientos adquiridos, la vivencia de su aplicabilidad en uno de los campos donde se puede desarrollar la especialización de auditoria hacen que se desarrollen las fortalezas que cada estudiante tiene en la toma de decisiones y en la crítica objetiva y neutral del proceso a evaluar, además de poder aportar de manera objetiva al mejoramiento continuo de este en cada una de sus etapas. 


\section{MARCO TEÓRICO}

En Colombia el sistema general de pensiones es un mecanismo por el cual se garantiza a la población el amparo bajo algunas circunstancias especiales como lo es la vejez, invalidez o muerte, bajo un reconocimiento económico o pensión según lo determine la Ley (1).

Bajo la anterior premisa, es importante mencionar que para que este reconocimiento económico sea efectivo los usuarios deben pasar por un proceso, en este caso se tomara el proceso de liquidación de incapacidades temporales en el cual intervienen tres partes la cuales son: un ente público como lo es Colpensiones quien se encarga del reconocimiento económico, una organización encargada de la recepción de los documentos radicados por el usuario y la auditoria de los mismos, y por ultimo una firma interventora quien se encarga de la vigilancia durante todo el proceso.

Partiendo de la idea de querer generar estrategias que garanticen un cumplimento oportuno en la liquidación de las incapacidades temporales radicadas por los usuarios al fondo de pensiones y la satisfacción de los mismos, se decide evaluar el proceso de auditoría de incapacidades temporales teniendo como fuente de información principal el cliente interno el cual nos mostrara las falencias.

La satisfacción se toma como elemento principal tanto para el cliente directo de la empresa como para el usuario o cliente externo, la cual tiene implícito varios factores que no son tangibles o medibles porque simplemente no se encuentran dentro de una lista de chequeo al momento de brindar un servicio, algunas de ellas puede ser la expectativa de atención con la que se dirige al cliente, la satisfacción de su necesidad al momento de obtener un resultado, el tiempo del proceso de atención, la fidelización del cliente, etc.

La oportunidad en tiempo de cumplimiento se tomará como punto clave en el desarrollo del proceso de satisfacción, culminación de metas, fidelización del cliente, disminución de procesos jurídicos y el cumplimiento del reconocimiento económico a los afiliados y a la organización. 


\section{Durante el proceso}

Muchas organizaciones basan el mejoramiento continuo en la respuesta favorable 0 desfavorable a una atención que recibió el cliente, sin embargo, la mayoría de ellas no se preparó para la demanda en los servicios prestados o simplemente fijaron su atención en la producción monetaria sin tener un estudio previo de mercadeo y por ello vemos como en ocasiones las organizaciones colapsan ya sea por la deficiente atención o por el mal direccionamiento de procesos.

Por ende es importante dar a conocer que la calidad vista desde el cliente se debe plantear como una estrategia que aporta en diferentes campos de la organización de manera lucrativa y formativa, siendo como parte fundamental la evaluación inicial del desarrollo de los procesos, durante la evolución y adhesión por parte del cliente interno, y la evaluación final donde el cliente externo es el responsable de darnos las pautas para una mejora continua, durante la atención dentro de la organización.

\section{Sistema general de pensiones}

El Sistema General de Pensiones tiene como objetivo garantizar a la población, el amparo contra las contingencias derivadas de la vejez, invalidez o muerte, mediante el reconocimiento de una pensión y prestaciones determinadas en la Ley (2), así como propender por la ampliación progresiva de cobertura a los segmentos de población no cubiertos con un sistema de pensiones (2).

Se aplicará a todos los habitantes del territorio nacional, conservando adicionalmente todos los derechos, garantías, prerrogativas, servicios y beneficios adquiridos y establecidos conforme a disposiciones normativas anteriores para quienes a la fecha de vigencia de esta Ley hayan cumplido los requisitos para acceder a una pensión o se encuentren pensionados por jubilación, vejez, invalidez, sustitución o sobrevivientes de los sectores público, oficial, semioficial, en todos sus órdenes, del Instituto de Seguros Sociales y del sector privado en general (2). 
Está compuesto por dos regímenes solidarios:

- Régimen Solidario de Prima Media con Prestación Definida;

- Régimen de Ahorro Individual con Solidaridad.

Características:

a) La afiliación es obligatoria salvo lo previsto para los trabajadores independientes;

b) La selección de uno cualquiera de los regímenes previstos por el artículo anterior es libre y voluntaria por parte del afiliado, quien para tal efecto manifestará por escrito su elección al momento de la vinculación o del traslado.

c) Los afiliados tendrán derecho al reconocimiento y pago de las prestaciones y de las pensiones de invalidez, de vejez y de sobrevivientes, conforme a lo dispuesto en la presente Ley;

d) La afiliación implica la obligación de efectuar los aportes que se establecen en esta Ley;

e) Los afiliados al Sistema General de Pensiones podrán escoger el régimen de pensiones que prefieran. Una vez efectuada la selección inicial, éstos sólo podrán trasladarse de régimen por una sola vez cada 3 años, contados a partir de la selección inicial, en la forma que señale el gobierno nacional;

f) Para el reconocimiento de las pensiones y prestaciones contempladas en los dos regímenes, se tendrá en cuenta la suma de las semanas cotizadas con anterioridad a la vigencia de la presente Ley, al Instituto de Seguros Sociales o a cualquier caja, fondo o entidad del sector público o privado, o el tiempo de servicio como servidores públicos, cualquiera sea el número de semanas cotizadas o el tiempo de servicio;

g) Para el reconocimiento de las pensiones y prestaciones contempladas en los dos regímenes se tendrá en cuenta la suma de las semanas cotizadas a cualquiera de ellos; 
h) En desarrollo del principio de solidaridad, los dos regímenes previstos por el artículo 12 de la presente Ley garantizan a sus afiliados el reconocimiento y pago de una pensión mínima en los términos de la presente Ley;

i) Existirá un Fondo de Solidaridad Pensional destinado a ampliar la cobertura mediante el subsidio a los grupos de población que, por sus características y condiciones socioeconómicas, no tienen acceso a los sistemas de seguridad social, tales como campesinos, indígenas, trabajadores independientes, artistas, deportistas y madres comunitarias;

j) Ningún afiliado podrá recibir simultáneamente pensiones de invalidez y de vejez;

k) Las entidades administradoras de cada uno de los regímenes del Sistema General de Pensiones estarán sujetas al control y vigilancia de la Superintendencia Bancaria (2).

Dentro de este régimen de pensiones el derecho a la población es el amparo y reconocimiento de una en una situación de las ya mencionadas al inicio de la descripción del sistema general de pensiones el cual comprende también el manejo y la sistematización del reconocimiento de las incapacidades temporales y el reconocimiento de las mismas a los ciudadanos.

Una incapacidad temporal es el reconocimiento de tipo económico y pago de la misma que hacen las EPS a sus afiliados cotizantes no pensionados, por todo el tiempo en que estén inhabilitados física o mentalmente para desempeñar en forma temporal su profesión u oficio habitual (12).

En materia de Riesgos Profesionales, el Artículo 2ํㅡ de la Ley 776 de 2002 define la incapacidad temporal como aquella que, según el cuadro agudo de la enfermedad o lesión que presente el afiliado al Sistema General de Riesgos Profesionales, le impida desempeñar su capacidad laboral por un tiempo determinado.

Se pueden clasificar en dos tipos:

- Incapacidad de origen común

- Incapacidad de origen profesional 
Una incapacidad común de acuerdo con el Parágrafo $1^{\circ}$ del Artículo 40 del Decreto 1406 de 1999, el cual fue modificado mediante Decreto 2943 del 17 de diciembre de 2013, estarán a cargo de los respectivos empleadores las prestaciones económicas correspondientes a los dos (2) primeros días de incapacidad originada por enfermedad general, tanto en el sector público como en el privado; y de las Entidades Promotoras de Salud a partir del tercer (3) día y de conformidad con la normatividad vigente (3).

En el Sistema General de Riesgos Laborales, las Administradoras de Riesgos Laborales reconocerán las incapacidades temporales desde el día siguiente de ocurrido el accidente de trabajo o la enfermedad diagnosticada como laboral (3).

El reconocimiento de las incapacidades posteriores a día 180 será asumido por las Entidades Promotoras de Salud, en caso de que la calificación de origen en la primera oportunidad sea común; o por la Administradora de Riesgos Laborales en caso de que la calificación del origen en primera oportunidad sea laboral y si existiese controversia continuarán cubriendo dicha incapacidad temporal de esta manera hasta que exista un dictamen en firme por parte de la Junta Regional o Nacional si se apela a esta, cuando el pago corresponda a la Administradora de Riesgos Laborales y esté en controversia, esta pagará el mismo porcentaje estipulado por la normatividad vigente para el régimen contributivo del Sistema General de Seguridad Social en Salud, una vez el dictamen esté en firme podrán entre ellas realizarse los respectivos reembolso y la ARP reconocerá al trabajador la diferencia en caso de que el dictamen en firme indique que correspondía a origen laboral (4).

Otra condicionante para este reconocimiento económico es el concepto favorable de rehabilitación que es otorgado por el especialista tratante del usuario que debe ser emitido en su EPS.

Este concepto está reglamentado dentro del artículo 142 del Decreto 019 de 2012 (5) donde ordena:

"Para los casos de accidente o enfermedad común en los cuales exista concepto favorable de rehabilitación de la Entidad Promotora de Salud, la Administradora de Fondos de Pensiones postergará el trámite de calificación de Invalidez hasta por un 
término máximo de trescientos sesenta (360) días calendario adicionales a los primeros ciento ochenta (180) días de incapacidad temporal reconocida por la Entidad Promotora de Salud, evento en el cual, con cargo al seguro previsional de invalidez y sobrevivencia o de la entidad de previsión social correspondiente que lo hubiere expedido, la Administradora de Fondos de Pensiones otorgará un subsidio equivalente a la incapacidad que venía disfrutando el trabajador.

Las Entidades Promotoras de Salud deberán emitir dicho concepto antes de cumplirse el día ciento veinte (120) de incapacidad temporal y enviarlo antes de cumplirse el día ciento cincuenta (150), a cada una de las Administradoras de Fondos de Pensiones donde se encuentre afiliado el trabajador a quien se le expida el concepto respectivo, según corresponda. Cuando la Entidad Promotora de Salud no expida el concepto favorable de rehabilitación, si a ello hubiere lugar, deberá pagar un subsidio equivalente a la respectiva incapacidad temporal después de los ciento ochenta (180) días iniciales con cargo a sus propios recursos, hasta cuando se emita el correspondiente concepto" (5).

Durante el proceso de auditoría de incapacidades se debe tener en cuenta las premisas anteriormente plasmadas para que los ciudadanos afiliado a un fondo de pensiones para que este se encargue del subsidio económico de la incapacidad a partir del día 181 y durante un periodo de 360 días continuos de incapacidad certificados por la EPS.

Para el desarrollo del proceso de auditoría de incapacidades temporales se debe tener en cuenta el protocolo de medicina laboral el cual da las pautas para la liquidación de las incapacidades a los usuarios.

Para la organización mundial de salud la medicina laboral o de trabajo es "La especialidad médica que, actuando aislada o comunitariamente, estudia los medios preventivos para conseguir el más alto grado posible de bienestar físico, psíquico y social de los trabajadores, en relación con la capacidad de estos, con las características y riesgos de su trabajo, el ambiente laboral y la influencia de este en su entorno; así como promueve los medios para el diagnóstico, tratamiento, adaptación, rehabilitación y calificación de la patología producida o condicionada por el trabajo" (11) 
Para Colpensiones la medicina laboral es un proceso donde se realizan las siguientes actividades: "aprobación, autorización y prorroga de las incapacidades mayores a 180 días, la calificación del estado de invalidez en primera oportunidad (PCL) derivada de accidente o enfermedad de origen común y la revisión del estado de invalidez cada 3 años cuando así lo considere" (6) (7).

Este proceso esta mediado por un tercero que es ASALUD, el cual se encarga de gestionar el proceso de auditoria en los procesos de calificación de pérdida de capacidad laboral e incapacidades temporales.

En este caso solo se tendrá en cuenta el proceso de auditoría de incapacidades temporales el cual se ha desarrollado en la medida de la exigencia del cliente más no desde una plataforma estratégica empresarial.

Para la evaluación de un proceso es importante definir que es un proceso, puesto que en la organización se menciona el término pero no se encuentra establecido y por ende no hay parámetros.

Un proceso administrativo se puede definir como el desarrollo de la actividad de administrar, ya que la administración comprende una serie de principios, fases, etapas y funciones, que deben cumplirse en forma metodológica pertinente para lograr el cumplimiento eficaz de los objetivos. La aplicación sucesiva de estas funciones en sus correspondientes etapas es el medio a través del cual se efectúa la administración, conformando así un proceso integral, que se conoce como proceso administrativo (13).

El conocimiento y dominio de estos conceptos y sus alcances, son indispensables para aplicar el método y las técnicas de esta disciplina, de manera correcta (13).

Dentro de un proceso se deben tener en cuenta que este debe contener algunos pasos que forman y le dan un peso de credibilidad; para Henri Fayol, a quién se considera el padre de la administración, pues sus teorías, principios y doctrinas han sido la base para la creación y sostenimiento de muchas organizaciones de esta rama (14), considera que un proceso debe ser organizado y coherente, como lo desarrolla en su 
teoría de administración donde plantea pautas que no necesariamente están obligadas a seguir pero al menos a tener en cuenta.

Fayol identificó 5 reglas o deberes de la administración (15) (16):

1. Planeación: diseñar un plan de acción para el mañana.

2. Organización: brindar y movilizar recursos para la puesta en marcha del plan.

3. Dirección: dirigir, seleccionar y evaluar a los empleados con el propósito de lograr el mejor trabajo para alcanzar lo planificado.

4. Coordinación: integración de los esfuerzos y aseguramiento de que se comparta la información y se resuelvan los problemas.

5. Control: garantizar que las cosas ocurran de acuerdo con lo planificado y ejecución de las acciones correctivas necesarias de las desviaciones encontradas.

Sin embargo Fayol da más importancia a que la administración se podía enseñar, le interesaba mucho mejorar la calidad de la administración y propuso varios principios para orientar el quehacer administrativo, los que se muestran a continuación (15):

- División del trabajo.

- Autoridad y responsabilidad.

- Disciplina.

- Unidad de mando.

- Unidad de dirección.

- Interés general sobre el individual.

- Justa remuneración al personal.

- Delegación vs. Centralización.

- Jerarquías.

- Orden.

- Equidad.

- Estabilidad del personal.

- Iniciativa. 
- Espíritu de equipo.

Estos principios administrativos no son de ninguna manera rígidos, ya que en diversas situaciones, se requiere hacer uso del criterio personal y la mesura. Lo más importante es que constituyen guías universales que en cualquier tipo de organización humana se pueden aplicar (16).

Para nuestro caso, dentro de la organización a pesar de que lleva mucho tiempo en el campo de la administración médica, aun no se han establecido un procesos estructurados y consecutivos, estos se manejan y desarrollan al conocimiento vago de algunos directivos o con relación a los requerimientos del cliente. Es aquí donde se ve la necesidad de realizar una evaluación de uno de los procesos.

Una evaluación la cual es parte final de un proceso y que contribuye al ciclo de mejoramuento, se puede tomar como una crítica para el avance pues es la que nos algunas pautas de falencias y fortalezas, en este caso en el proceso de auditoría de incapacidades temporales, al generar "evidencias" e información objetiva, permite a los coordinadores tomar decisiones fundamentadas y planear de forma estratégica (17).

Para el cumplimiento del objetivo general del proceso anteriormente mencionado se tendrá en cuenta una evaluación de efectos, que se fundamenta en valorar la contribución de la organización a los avances realizados para el logro de los efectos. Estos efectos son generalmente identificados en los marcos de resultados de los programas y proyectos a los cuales contribuyen al mejoramiento (17).

La evaluación por efectos proporciona (17):

- Evidencias para apoyar la rendición de cuentas de los procesos.

- Orientar la mejora del desempeño dentro de un programa vigente

- Identifica las áreas de fortaleza y debilidad

- La idoneidad de la estrategia de nuevas alianzas.

- Los impedimentos para lograr el efecto.

- Los ajustes a medio camino.

- Reforzar evaluaciones de nivel más alto y la planificación posterior. 
- Apoyar el aprendizaje sobre la evaluación de efecto en todo el proceso.

La evaluación de este proceso pretende que se tenga en cuenta ya que puede contribuir a la creación de nuevas estrategias para disminuir la oportunidad de gestión y liquidación de las incapacidades radicadas por los afiliados. 


\section{PROCESO DE AUDITORÍA DE INCAPACIDADES TEMPORALES}

La auditoría con el pasar de los años ha evolucionado en cuanto a su objetivo como consecuencia del desarrollo y tecnificación, que ha impactado al proceso de verificación, a la vez que ha permitido la extensión de su trabajo (18).

Es importante tener en cuenta que al evolucionar la auditoria en sus técnica, procedimientos y metodología para alcanzar sus propósitos, este trabajo debe tener un grado muy alto de detectar las irregularidades o ilícitos, pero no significa que este será su objetivo principal (18).

Cuando se realiza una auditoría de gestión la cual consiste en una evaluación independiente, objetiva y fiable donde las iniciativas, sistemas, operaciones, programas, actividades $u$ organizaciones funcionan bajo los principios organizacionales de economía, eficiencia y eficacia, y si existe margen de mejora (19), es donde el papel del auditor es clave para el cumplimiento del proceso ya que contribuye al cumplimiento de las metas propuestas, en este caso por parte de la organización y del cliente

Pensando en el ciudadano que radica sus incapacidades temporales (IT), se crea la necesidad en la cual reducir los tiempos es una opción de mejora durante el proceso, sin embargo, mientras se da a conocer el desarrollo del mismo se tendrá en cuenta el recurso humano requerido y las funciones que desempeña en cada etapa.

Recurso humano:

- Coordinación del proceso

- Auxiliar administrativo

- Ingeniero de sistemas

- Jefe de Enfermería

La radicación de los documentos se realiza en los PAC o sedes de la organización ubicadas en las diferentes ciudades del país, donde se dirigen los usuarios con los documentos completos y solicitados para el reconocimiento económico. 
En las sedes o PAC son atendidos por el personal auxiliar administrativo quienes se encargan de la recepción de los documentos por medio de un formato de entrega de documentos (FED) (anexo 1), donde se diligencia una lista de chequeo y se adjunta la documentación entregada por el usuario, durante este proceso se genera un radicado al usuario para que realice las consultas futuras y se organiza los casos o paquetes para ser enviados a diario a la sede principal.

Proceso: se lleva a cabo en varias etapas:

\section{Etapa 1}

Cuando el caso llega a la sede principal es recibido por el auxiliar administrativo el cual se encarga de generar la cita con el radicado creado para cada caso y realiza un conteo de las IT los cuales quedan registrados en el aplicativo SAMI.

\section{Etapa 2}

El caso pasa a la etapa de escaneo, donde se verifica la creación de la cita y se realiza el escaneo de cada uno de los documentos los cuales son:

- Formato de entrega de documentos (FED).

- Fotocopia del documento de la identificación del usuario.

- Incapacidades temporales.

- Certificado de record de incapacidades (CRI).

- Certificado de rehabilitación (CRE).

- Certificación original bancaria (COB).

- Autorización a terceros del COB.

Los documentos se cargan al aplicativo SAMI, en el módulo visor documental (ver imagen 1), teniendo en cuenta un orden determinado por la organización para facilitar la auditoria de cada caso. 
Imagen 1. Visor Documental

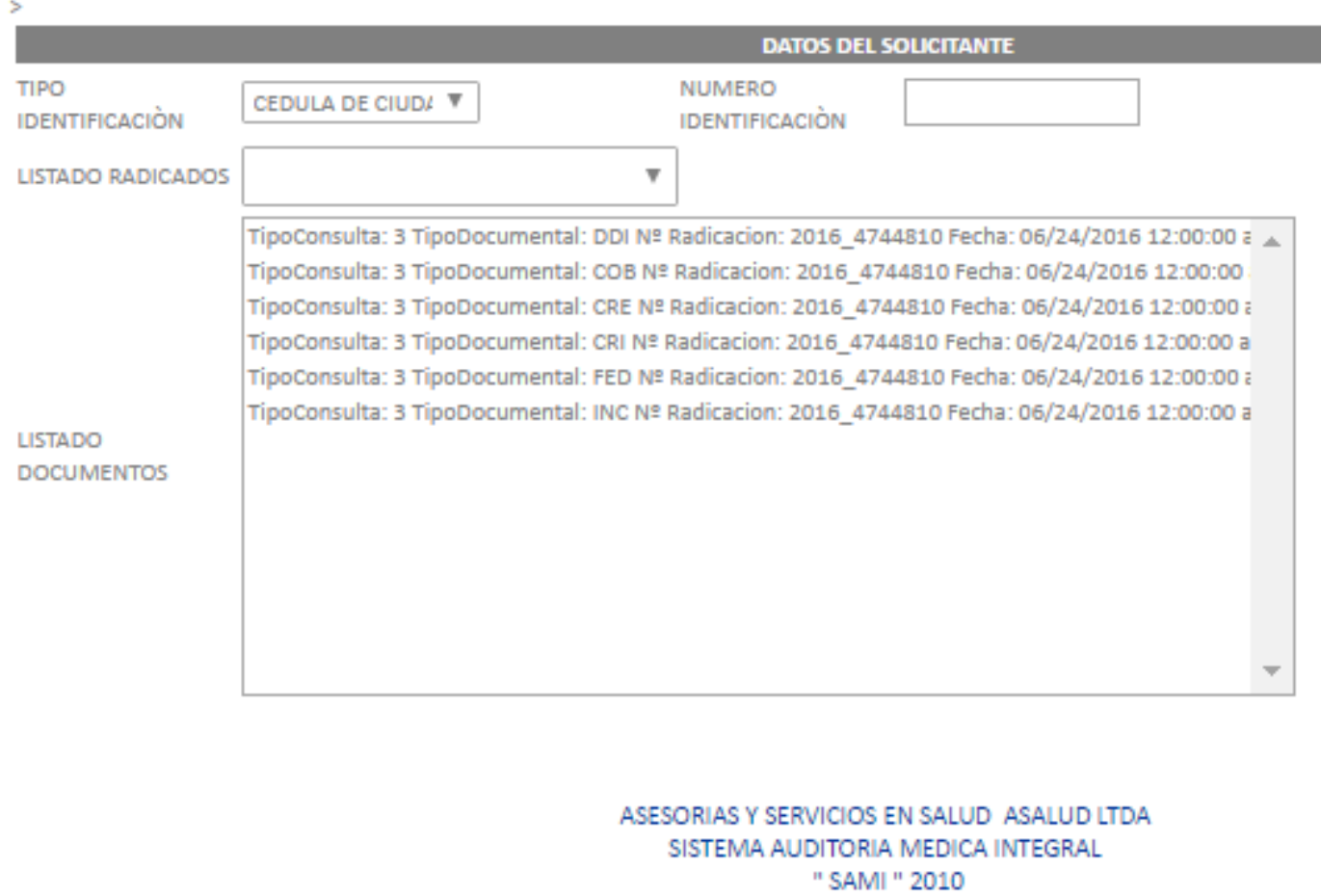

Fuente: tomado de aplicativo empresarial, SAMI, cargue de documentos.

\section{Etapa 3}

Los casos se cargan en una base de datos inmersa en SAMI, la cual es descargada y analizada por el ingeniero de sistemas, donde hay una clasificación teniendo en cuenta las variables como: la fecha de recibido y escaneo, numero de IT, auditor, prioridad, numero de id, identificación del usuario, radicado y estado.

Ingeniero de sistemas es el encargado de realizar una hoja de ruta (ver imagen 2) a partir de la base de datos arrojada por SAMI donde está la asignación de casos diaria de manera equitativa, la producción de cada auditor, el estado resolutivo de cada caso, los pendientes y la trazabilidad de la gestión realizada para el cumplimiento de las metas propuestas por la organización. 
Imagen 2. Hoja De Ruta Incapacidades.

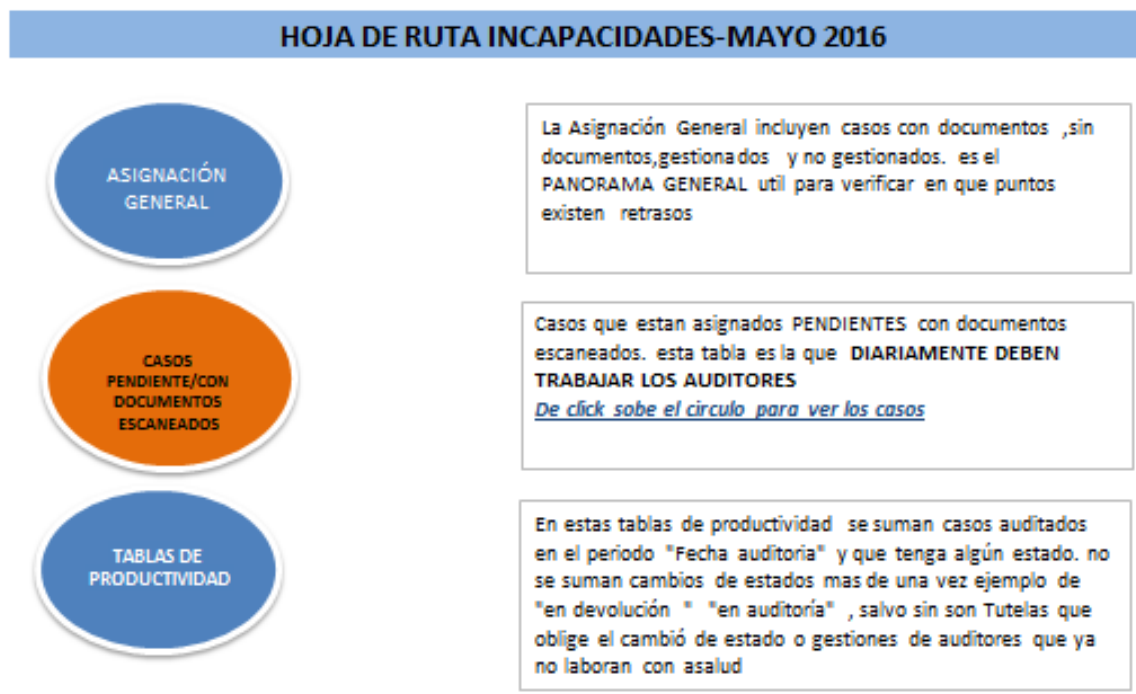

CASOS EN VALIDACION DE DERECHOS

Fuente: tomada de hoja de ruta del proceso de incapacidades.

\section{Etapa 4}

En esta etapa la cual es el final del proceso los casos son auditados por los enfermeros jefes, quienes se encargan de verificar en el aplicativo SAMI que los documentos estén completos, que cumplan con los requerimientos establecidos y le dan un estado al caso.

Cuando se inicia con la auditoria de IT los casos pueden tomar dos rutas: la primera es validación de derechos y la segunda un estado resolutivo, ya sea auditoria, seguimiento al ciudadano y cierre administrativo. 


\section{Estados del caso:}

Validación de derechos: este, aunque no es un estado como tal, es una parte del proceso por el cual deben pasar todos los casos radicados por los usuarios, ya que es la parte donde el cliente (Colpensiones) se encarga de verificar si el paciente tiene las semanas de cotización con la AFP, si aún está cotizando, si tiene los 180 días continuos de incapacidad y determina el ingreso base de cotización (IBC).

Para que un caso se envié a validación de derechos (ver imagen 3) es necesario contar con un CRI el cual muestre 180 días continuos de incapacidad, sin interrupción, con el mismo diagnóstico y no necesariamente que estos días estén pagos por la EPS, se debe colocar la fecha inicial, la cual es donde inicia su primera IT y la fecha final o día 180.

Imagen 3. Validación de derechos.

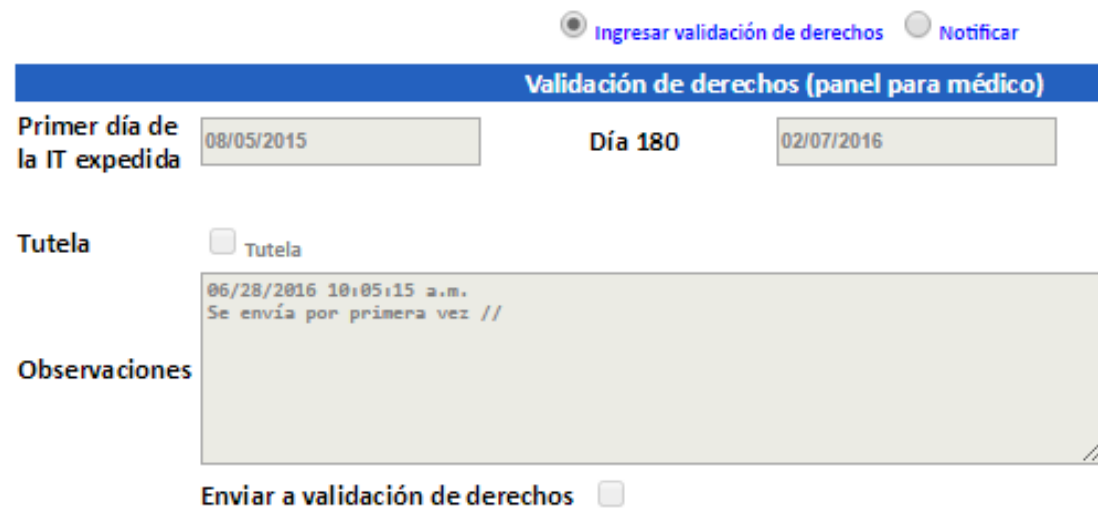

Validación de derechos (panel para auditores)

La incapacidad fue enviada a pre-auditoría

Fuente: tomada de aplicativo SAMI, validación de derechos.

Seguimiento al ciudadano: para que un caso termine en este estado es porque durante la auditoria se puede encontrar los siguientes criterios: 
- Le hace falta algunos de los documentos que se solicitan para la auditoria de incapacidades (FED, DDI, CRI, CRE, IT, COB)

- EI CRI no tiene los 180 días de incapacidad continuos.

- Por CRI desactualizado: quiere decir que las IT radicadas no están en el CRI.

- El CRE es indeterminado.

- Algunas IT no están transcritas.

- No tiene autorización a un tercero la cuenta bancaria.

Con los anteriores motivos se cargan a una bandeja de entrada de la plataforma en call center quienes se encargan de comunicarse con el usuario y solicitar la necesidad del caso para ser enviado a auditar.

El caso tiene un periodo de 45 días para estar en seguimiento al ciudadano, durante este tiempo se le realizan 3 llamadas cada 15 días para hacer la verificación y respectiva notificación al usuario ante la solicitud del documento faltante, después de la caducidad de los 45 días, se da cierre administrativo automáticamente y se notifica por medio de una carta al paciente y a Colpensiones.

Cierre administrativo: cuando un caso se le da cierre administrativo es porque cumple con algunos requisitos como lo son:

- CRE desfavorable.

- IT anteriores a día 180.

- IT posteriores a día 540.

- IT posteriores a calificación de pérdida de capacidad laboral.

- Todas las IT no estas transcritas.

- IT sin tiempo de cotización.

- IT de origen laboral.

- Usuario fallecido.

- Casos tutela.

- Todas las IT están repetidas. 
Después de que se da cierre administrativo por los motivos ya mencionados, se genera una carta automáticamente en el aplicativo SAMI, donde está el motivo de negación, los periodos de IT radicados y los datos personales del usuario, se hace revisión de pertinencia de la notificación y se envía a Colpensiones para que se avale el cierre administrativo y por medio de correo certificado se envía la carta de notificación al usuario.

Auditoria: el caso que se envía auditoria de Colpensiones es porque cumple con los criterios de auditoria, en este momento el caso pasa por una segunda auditoria por parte del cliente quien pude direccionar el caso según su criterio a estados como: 1. devolución, que significa que el caso puede tener algún error y devuelven para subsanar la falencia, 2. corrección de historia laboral, son los casos que por algún motivo el periodo de la IT no se le reconoció a la AFP, por lo tanto se notifica al usuario para que el realice la respectiva aclaración y 3.liquidacion de incapacidad, a lo que hace referencia este último es que las IT serán reconocidas económicamente por parte de la AFP. 


\section{METODOLOGÍA}

La evaluación del proceso de auditoría de incapacidades se realiza con el fin de identificar las falencias durante el proceso y poder generar algunas estrategias de mejora para disminuir los tiempos de gestión y acelerar la liquidación de las IT radicadas, al usuario.

Durante el proceso de auditoria intervienen varios actores que deben estar presentes para el control de los documentos radicados por los usuarios. Para realizar esta evaluación se ha tomado como base la información dada por uno de los coordinadores del proceso en ASALUD LTDA en colaboración de una enfermera jefe auditor, los cuales proporcionan información acerca de los tiempos que tardan en llegar los casos a la sede principal y en ser gestionados.

Se realiza una evaluación durante el mes de mayo del 2016 por medio de la observación durante la auditoria de IT que se gestiona para medir el tiempo que se demora en cada uno de los auditores en la gestión y definición de estado de los diferentes casos.

\section{POBLACIÓN Y MUESTRA:}

Para la definición de la muestra se decidió tomar a dos de los tres jefes de enfermería que auditan los casos en el proceso de auditoría de incapacidades temporales, teniendo en cuenta que uno tiene más experiencia que el otro.

\section{RECOLECCIÓN DE DATOS Y ANALISIS DE INFORMACIÓN:}

Para la recolección de información fue necesario tomar datos durante la auditoria de incapacidades temporales a los jefes que perteneces a la prueba de evaluación del proceso en el cual se les tomara el tiempo gastado durante la auditoria de un caso hasta la asignación de un estado. 
Para la medición es necesario tener en cuenta 4 etapas del proceso, se usa un formato donde se pueda recolectar la información que se necesita para la medición de tiempos en la gestión de casos como se muestra a continuación.

\section{Tabla 1. Formato de medición de tiempos.}

\begin{tabular}{|l|c|c|c|c|}
\hline Numero de IT & $\begin{array}{c}\text { Medición de tiempos (minutos) } \\
\text { Rocumental } \\
\text { Hora de inicio }\end{array}$ & Ingreso de IT & $\begin{array}{c}\text { Estado de } \\
\text { caso }\end{array}$ & $\begin{array}{c}\text { Total tiempo } \\
\text { (min) }\end{array}$ \\
\hline & & & & \\
\hline & & & & \\
\hline & & & & \\
\hline
\end{tabular}

El evaluador se sienta con cada uno de los auditores para medir el tiempo que tardan en auditar un caso de donde teniendo en cuenta las variables para definir un tiempo estándar en la gestión de los casos. 


\section{RESULTADOS}

Durante la observación se aplica el formato creado para la medición de tiempos a los auditores durante la gestión del proceso de auditoría de incapacidades temporales se recolecta los siguientes datos para determinar tiempos y movimientos, que se dan a conocer en la presentación de tablas donde dinámicas obtenidas del área de procesos.

En el proceso de evaluación se tiene en cuenta la medición de tiempos y movimientos de dos auditores que trabajan con el proyecto

El auditor administrativo dentro de la organización debe ser profesional, debe contar con una preparación acorde con los requerimientos de una auditoria administrativa, ya que eso le permitirá interactuar de manera natural y congruente con los mecanismos de estudio que de una u otra manera se emplearán durante su desarrollo (20).

El auditor deberá garantizar (19) (20):

- Un proceso de fiscalización basado en un criterio válido.

- El uso y la combinación de las metodologías adecuadas para recabar un conjunto de datos.

- El planteamiento de preguntas de auditoría de las que se puedan extraer conclusiones y generen aportes a la mejora del proceso.

- La utilización de los instrumentos necesarios para facilitar la correcta realización de la gestión.

- La obtención de pruebas suficientes, pertinentes y fiables para apoyar los resultados.

- La transparencia.

- Actitud positiva.

- Estabilidad emocional.

- Objetividad.

- Sentido institucional.

- Saber escuchar. 
- Creatividad.

- Respeto a las ideas de los demás.

- Mente analítica.

Dentro de la evaluación del proceso de auditoría de IT se evalúan a dos auditores del proceso, descritos a continuación.

Auditor 1: profesión: enfermero jefe, el cual tiene más experiencia en el desarrollo del proceso ya ha estado en continua capacitación de los cambios que se han generado en el proyecto, el tiempo que lleva en la empresa y como auditor de incapacidades es de un año y 6 meses.

Auditor 2: profesión: enfermero jefe, tiene menos experiencia en la auditoria de IT, no se capacito de manera completa en el manejo del proceso, el tiempo que lleva con la empresa y como auditor de incapacidades lleva 2 meses.

A continuación se da a conocer las cifras de gestión de casos tramitados en el mes de mayo tomado del informe presentado a Colpensiones: Medicina Laboral, Gestión Mes De Mayo.

Tabla 2. Informe a corte de 2 mayo de 2016

\begin{tabular}{|l|l|r|r|r|}
\hline \multicolumn{1}{|c|}{ Estado } & \multicolumn{1}{|c|}{ Gestion } & Cant Radicados & Cert Incapacidad & $\%$ Incapacidades \\
\hline En auditoría Colpensiones & Colpensiones & 754 & 3.762 & $20,7 \%$ \\
\hline En devolución al tercero & Asalud & 327 & 2.154 & $11,8 \%$ \\
\hline En revision documental & Asalud & 2.895 & 8.422 & $46,3 \%$ \\
\hline Historia Laboral & Colpensiones & 73 & 243 & $1,3 \%$ \\
\hline Seguimiento al ciudadano & Asalud/Afiliado & 615 & 2.519 & $13,9 \%$ \\
\hline Tramite operativo Asalud & Colpensiones & 246 & 810 & $4,5 \%$ \\
\hline Validados sin derechos & Finalizado & 43 & 276 & $1,5 \%$ \\
\hline Total general & & $\mathbf{4 . 9 5 3}$ & $\mathbf{1 8 . 1 8 6}$ & $\mathbf{1 0 0 \%}$ \\
\hline
\end{tabular}

\begin{tabular}{c|c|c|c|} 
SEMANA ANTERIOR & PROCESAMOS & RECIBIMOS & TOTAL \\
\hline 19610 & 4094 & 2670 & 18186 \\
\hline & * Inlcuir en liquidación \\
\hline & * Cierre Administrativo
\end{tabular}


Se puede observar que se inicia con 19610 incapacidades pendientes por tramitar del mes de abril, en la primera semana de mayo se procesaron 4094 y se recibieron 2670 , en total se registraron 18186, lo que muestra una gestión de 1424, lo cual no es significativo para el cliente ni para la organización.

Tabla 3. Informe a corte de 7 mayo de 2016

\begin{tabular}{|c|c|c|c|}
\hline ESTADO & $04 / 05 / 2016$ & $11 / 05 / 2016$ & GESTION \\
\hline Nuevas (ingresaron en la semana) & & 1.481 & NUEVOS \\
\hline En auditoría & 3.762 & 3.233 & BAJO \\
\hline En devolución al tercero Asalud & 2.154 & 1.358 & BAJO \\
\hline En revisión documental & 8.422 & 6.513 & BAJO \\
\hline Historia Laboral & 243 & 293 & SUBIO \\
\hline Seguimiento al ciudadano & 2.519 & 2.631 & SUBIO \\
\hline Tramite Operativo Asalud & 810 & 405 & BAJO \\
\hline En validación derechos & 276 & - & BAJO \\
\hline Planilla de liquidación* & & 2.255 & FINALIZADO \\
\hline Finalizados* & & 1.498 & FINALIZADO \\
\hline Total general certificados de incapacidad & 18.186 & 15.914 & \\
\hline Total general radicados & 4.953 & 4.464 & \\
\hline Total general cédulas & 3.216 & 3.080 & \\
\hline
\end{tabular}

\begin{tabular}{|c|c|r|r|} 
& & & \\
SEMANA ANTERIOR & PROCESADOS & NUEVOS & PENDIENTE AL CIERRE \\
\hline 18186 & 3.753 & 1.481 & 15.914 \\
\hline
\end{tabular}

*Estados cierre administrativo, Incluir en liquidación 3,753

* gestion semana todos los estados 5,359

Fuente: Tomado de informe a Colpensiones mes de mayo 2016

Teniendo en cuenta que las IT pendientes por tramitar son 18186, en la segunda semana de mayo se procesan 3753 y se reciben 1481, en total se registraron 15914, lo que muestra una gestión de 2272, lo cual no es significativo para el cliente ni para la organización. 


\section{Tabla 4. Informe a corte de 11 mayo de 2016}

\begin{tabular}{|c|c|c|c|c|c|c|}
\hline \multicolumn{2}{|l|}{ Total } & \multicolumn{2}{|c|}{ 05/11/2016 } & \multicolumn{2}{|c|}{$05 / 18 / 2016$} & \\
\hline \multicolumn{2}{|l|}{ Nuevas Semanas"*** } & & 1.481 & & 1.608 & Aumento \\
\hline \multicolumn{2}{|l|}{ En auditoria Colpensiones } & & 3.233 & & 2.452 & Disminuyo \\
\hline \multicolumn{2}{|c|}{ En devolucion al tercero Asalud } & & 1.358 & & 1.149 & Disminuyo \\
\hline \multicolumn{2}{|c|}{ En revision documental Asalud } & & 6.513 & & 7.492 & Aumento \\
\hline \multicolumn{2}{|c|}{ Historia Laboral Colpensiones } & & 293 & & 308 & Aumento \\
\hline \multicolumn{2}{|l|}{ Seguimiento al ciudadano } & & 2.631 & & 2.064 & Disminuyo \\
\hline \multicolumn{2}{|l|}{ Tramite opertativo Asalud } & & 405 & & 183 & Disminuyo \\
\hline \multicolumn{2}{|l|}{ En validacion de derechos } & & 0 & & 0 & \\
\hline \multicolumn{2}{|l|}{$\begin{array}{c}\text { Totales } \\
\end{array}$} & & 15.914 & & 13.648 & \\
\hline \multicolumn{2}{|l|}{ Radicados } & & 4.464 & & 4.064 & \\
\hline \multicolumn{2}{|l|}{ Cedulas } & & 3.080 & & 2.830 & \\
\hline SALDO ANTERIOR & \multicolumn{2}{|c|}{ PROCESADOS } & & NUEVOS & \multicolumn{2}{|c|}{ PENDIENTE AL CIERRE } \\
\hline \multirow[t]{3}{*}{15914} & & 3874 & & 1608 & & 13648 \\
\hline & \multicolumn{6}{|c|}{ * Estado aprobado y cierre administrativo } \\
\hline & \multicolumn{6}{|c|}{ * Gestion semana todos los estados 5925} \\
\hline
\end{tabular}

Fuente: Tomado de informe a Colpensiones mes de mayo 2016

Para la tercera semana las IT pendientes por tramitar son 15914, se procesan 3874 y se reciben 1608 , en total se registraron 13648, lo que muestra una gestión de 2266, lo cual no es significativo para el cliente ni para la organización. 
Tabla 5. Informe a corte de 25 mayo de 2016

\begin{tabular}{|l|r|r|r|}
\hline Estado & $\mathbf{2 5 / 0 5 / 2 0 1 6}$ & $\mathbf{3 0 / 0 5 / 2 0 1 6}$ & cc unica \\
\hline En auditoría & 2.138 & 873 & 182 \\
\hline Tramite operativo & 53 & 81 & 39 \\
\hline En devolución al tercero & 981 & 1.179 & 222 \\
\hline En validacion derechos & 477 & 115 & 22 \\
\hline Historia Laboral & 217 & 181 & 40 \\
\hline Revision documental & 5.528 & 6.347 & 1.920 \\
\hline Seguimiento al ciudadano & 2.334 & 2.486 & 569 \\
\hline Total general & 11.728 & 11.262 & 2.643 \\
\hline Radicados & 3722 & 3661 & \\
\hline Cedulas & 2664 & 2643 & \\
\hline
\end{tabular}

\begin{tabular}{r|r|r|r|r|} 
Semana Anterior & Nuevos Semana & TOTAL & PROCESADOS & TOTAL AL CORTE \\
\hline 11.728 & 2.475 & 14.203 & 2.941 & 11.262 \\
\hline
\end{tabular}

Fuente: Tomado de informe a Colpensiones mes de mayo 2016

Para la cuarta semana las IT pendientes por tramitar son 11728, se procesan 2941 y se reciben 2475 , en total se registraron 11262 , lo que muestra una gestión de 466, lo cual no es significativo para el cliente ni para la organización. 
Tabla 6. Informe a corte de 30 mayo de 2016

\begin{tabular}{|l|r|r|r|}
\hline Estado & $\mathbf{3 0 / 0 5 / 2 0 1 6}$ & $\mathbf{0 7 / 0 6 / 2 0 1 6}$ & \multicolumn{1}{c|}{ cc unica } \\
\hline En auditoría & 873 & 815 & $\mathbf{2 3 0}$ \\
\hline Trámite operativo & 81 & 157 & 89 \\
\hline En devolución al tercero & 1.179 & 752 & 176 \\
\hline En validacion derechos & 115 & 482 & 120 \\
\hline Historia Laboral & 181 & 193 & 45 \\
\hline Revisión documental & 6.347 & 4.937 & 1.517 \\
\hline Seguimiento al ciudadano & 2.486 & 2.619 & 582 \\
\hline Total general & 11.262 & $\mathbf{9 . 9 5 5}$ & \\
\hline Radicados & 3.661 & 3.183 & \\
\hline Cedulas & 2.664 & 2.357 & \\
\hline
\end{tabular}

\begin{tabular}{r|r|r|r|r|} 
Semana Anterior & Nuevos Semana & TOTAL & PROCESADOS & TOTAL AL CORTE \\
\hline 11.262 & 2.099 & 13.361 & 3.406 & 9.955 \\
\hline
\end{tabular}

Fuente: Tomado de informe a Colpensiones mes de mayo 2016

Durante la quita semana las IT pendientes por tramitar son 11262, se procesan 3406 y se reciben 2099, en total se registraron 9955, lo que muestra una gestión de 1307, lo cual no es significativo para el cliente ni para la organización.

Durante el mes de mayo no se pudo evidenciar un avance significativo en la gestión y procesamiento de incapacidades temporales en la contingencia organizada por la coordinación del proceso, esto obligo a tener en cuenta el tiempo que se demoran en procesar cada caso, para ello es necesario que se realice una medición de tiempos y movimientos.

El estudio de tiempos y movimientos es una herramienta para la medición del trabajo utilizada con éxito desde finales del Siglo XIX, cuando fue desarrollada por Taylor. A través de los años dichos estudios han ayudado a solucionar multitud de problemas de producción y a reducir costos (8). 
Estudio de tiempos: actividad que implica la técnica de establecer un estándar de tiempo permisible para realizar una tarea determinada, con base en la medición del contenido del trabajo del método prescrito, con la debida consideración de la fatiga y las demoras personales y los retrasos inevitables (8).

Estudio de movimientos: análisis cuidadoso de los diversos movimientos que efectúa el cuerpo al ejecutar un trabajo (8).

Para la medición de tiempos y movimientos hay que considerar básicamente los siguientes aspectos (8).

- Para obtener un estándar es necesario que el operario domine a la perfección la técnica de la labor que se va a estudiar.

- El método a estudiar debe haberse estandarizado

- El empleado debe saber que está siendo evaluado, así como su supervisor y los representantes.

- El analista debe estar capacitado y debe contar con todas las herramientas necesarias para realizar la evaluación

- El equipamiento del analista debe comprender al menos un cronómetro, una planilla o formato preimpreso y una calculadora. Elementos complementarios que permiten un mejor análisis son la filmadora, la grabadora y en lo posible un cronómetro electrónico y una computadora personal.

- La actitud del trabajador y del analista debe ser tranquila y el segundo no deberá ejercer presiones sobre el primero

Hay dos métodos básicos para realizar el estudio de tiempos, el continuo y el de regresos a cero.

En el método continuo se deja correr el cronómetro mientras dura el estudio. En esta técnica, el cronómetro se lee en el punto terminal de cada elemento, mientras las manecillas están en movimiento. En caso de tener un cronómetro electrónico, se puede proporcionar un valor numérico inmóvil. 
En el método de regresos a cero el cronómetro se lee a la terminación de cada elemento, y luego se regresa a cero de inmediato. Al iniciarse el siguiente elemento el cronómetro parte de cero. El tiempo transcurrido se lee directamente en el cronómetro al finalizar este elemento y se regresa a cero otra vez, y así sucesivamente durante todo el estudio (8) (9).

Para la medición de tiempos y movimientos durante la gestión y auditoria de casos en ASALUD LTDA en el proyecto de Colpensiones se utiliza el método continuo.

A continuación de muestra las mediciones se tomadas en minutos, se ubicó dos columnas comparativas del auditor 1 y 2 , las cuales muestran el tiempo que se gasta durante la auditoria de incapacidades temporales teniendo en cuenta el número de IT y que los casos tomados de muestra serán para quedar en un estado de auditoria.

La recolección de datos durante la observación se presenta en las siguientes tablas obtenidas de la auditoria de incapacidades temporales, las cuales presentan los tiempos de los auditores y sus promedios.

\section{Tabla 7. Auditoria de casos de 1 IT}

\begin{tabular}{|l|r|r|}
\hline ETAPAS/ 1 IT & Suma de auditor 1 & Suma de auditor 2 \\
\hline ESTADO DE CASO & 2 & 2 \\
\hline INGRESO IT & 1 & 2 \\
\hline REVISION DOCUEMETAL & 3 & 6 \\
\hline Total, general & $\mathbf{6}$ & $\mathbf{1 0}$ \\
\hline
\end{tabular}

El promedio de tiempo que se puede tomar en la auditoria de casos de una 1 IT para el auditor 1 es de 6 minutos y para el auditor 2 es de 10 minutos, y el promedio de los dos auditores es de 8 minutos. 
Tabla 8. Auditoria de casos de 3 IT

\begin{tabular}{|l|r|r|}
\hline ETAPAS/ 3 IT & Suma de auditor 1 & Suma de auditor 2 \\
\hline ESTADO DE CASO & 1 & 2 \\
\hline INGRESO IT & 2 & 3 \\
\hline REVISION DOCUEMETAL & 3 & 6 \\
\hline Total, general & $\mathbf{6}$ & $\mathbf{1 1}$ \\
\hline
\end{tabular}

El promedio de tiempo que se puede tomar en la auditoria de casos de 3 IT para el auditor 1 es de 2 minutos y para el auditor 2 es de 3.6 minutos por cada IT y el promedio de los dos auditores es de 8.5 minutos.

Tabla 9. Auditoria de casos de 5 IT

\begin{tabular}{|l|r|r|}
\hline ETAPAS/ 5 IT & Suma de auditor 1 & \multicolumn{2}{l|}{ Suma de auditor 2} \\
\hline ESTADO DE CASO & 1 & 2 \\
\hline INGRESO IT & 2 & 3 \\
\hline REVISION DOCUEMETAL & 5 & 10 \\
\hline Total, general & $\mathbf{8}$ & $\mathbf{1 5}$ \\
\hline
\end{tabular}

El promedio de tiempo que se puede tomar en la auditoria de casos de 5 IT para el auditor 1 es de 1.6 minutos y para el auditor 2 es de 3 minutos por cada IT y el promedio de los dos auditores es de 11.5 minutos.

Tabla 10. Auditoria de casos de 10 IT

\begin{tabular}{|l|r|r|}
\hline ETAPAS/ 10 IT & Suma de auditor 1 & Suma de auditor 2 \\
\hline ESTADO DE CASO & 2 & 2 \\
\hline INGRESO IT & 4 & 8 \\
\hline REVISION DOCUEMETAL & 7 & 10 \\
\hline Total, general & 13 & 20 \\
\hline
\end{tabular}


El promedio de tiempo que se puede tomar en la auditoria de casos de 10 IT para el auditor 1 es de 1.3 minutos y para el auditor 2 es de 2 minutos por cada IT y el promedio de los dos auditores es de 16.5 minutos.

Tabla 11. Auditoria de casos de 24 IT

\begin{tabular}{|l|r|r|}
\hline ETAPAS/ 24 IT & Suma de auditor 1 & Suma de auditor 2 \\
\hline ESTADO DE CASO & 2 & 2 \\
\hline INGRESO IT & 8 & 15 \\
\hline REVISION DOCUEMETAL & 4 & 10 \\
\hline Total, general & $\mathbf{1 4}$ & $\mathbf{2 7}$ \\
\hline
\end{tabular}

El promedio de tiempo que se puede tomar en la auditoria de casos de 24 IT para el auditor 1 es de 0.6 minutos y para el auditor 2 es de 1.2 minutos por cada IT y el promedio de los dos auditores es de 20.5 minutos. 


\section{RECOMENDACIONES}

Durante la evaluación del proceso de auditoría de incapacidades temporales se

evidencia la necesidad de un planteamiento de cambio para generar un mejoramiento integral del proceso.

Las sugerencias se realizarán por etapas:

\section{Etapa 1}

- El personal que hace la recepción los casos no cuenta con el conocimiento y desarrollo del proceso, por lo cual hay acumulación de casos en las sedes originando así una prolongación los tiempos en la gestión de auditoria, por ende, es necesario que se capacite al personal en el proceso de auditoría de IT.

- El personal no es suficiente para el volumen de afiliados con el que cuenta Colpensiones, los auxiliares administrativos tienen múltiples funciones, en las sedes no hay control ni manejo del proceso y los casos, por lo cual es pertinente el aumento de recurso humano en las sedes.

\section{Etapa 2}

- El personal que se encarga de realizar el escaneo de los casos no es suficiente para la demanda de los 12 jefes auditores con los que contamos en este momento, puesto que dos auxiliares administrativos no dan abasto para asignación de casos suficientes para cumplir las metas de cada auditor.

- La contratación de recurso humano en las áreas anteriormente descritas podría disminuir los tiempos de gestión de los casos y agilizar el proceso de auditoría, evitando así la represa de casos, los errores de escaneo y de creación de citas, y la calidad mejoraría ante el cliente.

- El aumento del recurso humano en esta área evitaría la represa de casos pendientes y la oportunidad en gestión se reduciría, sin contar que las liquidaciones de las IT a lo usuario serian en un menor tiempo. 


\section{Etapa 3}

- En esta etapa de asignación de casos, se puede evidenciar que no haya una precisión en el conocimiento de cantidad y control de lo que a diario entra, de los casos recibidos en el sistema, de lo escaneado, y de lo que realmente se debe asignar, lo que acarrea que se asignen casos sin documentos, sin la creación de citas, el mal conteo del record de incapacidades de cada jefe auditor, sin dejar a un lado que el desconocimiento que se tiene en el proceso de auditoría de incapacidades con cada caso radicado por el usuario.

- Es importante que el ingeniero de sistemas, quien es el encargado de manejar la hoja de ruta y la asignación de casos se capacite en el tiempo que se puede gastar en la auditoria de incapacidades, pues es evidente el desconocimiento del manejo de los casos y su estado.

- Es importante que se tenga en cuenta la igualdad en la asignación de IT a los jefes auditores que cumplen con una meta mensual.

\section{Etapa 4}

En esta etapa, el encargado de los procesos es el jefe auditor de incapacidades el cual se encarga de la revisión completa de cada caso.

- La validación de derechos debe ser más oportuna, se tardan más 3 días en validar un caso.

- El aplicativo SAMI debe ser completamente eficaz y eficiente, para agilizar la auditoria de cada uno de los casos, su reproceso interviene en los tiempos y movimientos de la gestión de las IT.

- La medición del número de IT se debe hacer sobre la gestión realizada teniendo en cuenta la totalidad de los casos, puesto que en algunas ocasiones se le debe realizar varias reaperturas a un mismo caso, teniendo en cuenta su estado.

- En el mes de mayo ingresaron jefes nuevos al proceso, los cuales no tiene una capacitación integral del proceso de auditoría de IT, lo cual genera que la una auditoria deficiente que se ve a reflejada en el retraso de la liquidación de las incapacidades a los usuarios. 
- El aumento del personal en esta área hace que las metas impuestas no sean fáciles de cumplir, ya que la demanda no es satisfecha por el volumen de casos escaneados.

- Evaluar el proceso de auditoría de incapacidades temporales en el proyecto de COLPENSIONES con ASALUD LTDA durante el mes de mayo del 2016.

\section{Objetivos Específicos}

- Establecer tiempos y movimientos de los casos que se gestionan en ASALUD LTDA durante el proceso de auditoria en incapacidades a los profesionales encargados.

- Sugerir un plan de mejoramiento que se pueda ver reflejado en la disminución de los requerimientos jurídicos y promueva la gestión oportuna en la liquidación a los usuarios de los casos radicados.

¿La evaluación del proceso en auditoría de incapacidades temporales, permite mejorar la gestión oportuna para la liquidación de las mismas con relación a los tiempos en que se gestiona cada caso durante el periodo de mayo del 2016 ? 


\section{CONCLUSIONES}

- Al realizar la evaluación del proceso de auditoría de incapacidades se puede evidenciar que no es oportuna la gestión de cada caso auditado lo que retrasa la liquidación a los usuarios.

- La oportunidad de gestión de un caso está a 15 días desde que el usuario radica en las sedes o PAC.

- La oportunidad sería menor si la organización realizara una inversión a nuevas estrategias de calidad y recurso humano generando así una mayor productividad de la organización.

- La medición de tiempos y movimientos es un proceso que deja conocer los índices de productividad y capacitación del personal con el que se cuenta para que se vea reflejado en remuneración económica.

- La evaluación como herramienta es muy constructiva y más aún vista desde la parte académica donde el auditor debe vencer miedos y poner retos de conocimientos y aptitudes.

- El proceso de incapacidades temporales, aunque es muy corto y dinámico aun le hace falta una estructura organizacional.

- Es importante resaltar la manera en como la organización ha tratado de cumplir con las metas propuestas y como se está logrando, al incluir recurso humano en la auditoria de incapacidades.

- Las capacitaciones continuas de los cambios del proceso y los avances de gestión positivos son importantes que se den a conocer a los integrantes del proyecto, esto genera en el personal una ambiente de trabajo en equipo. 


\section{BIBLIOGRAFÍA}

1. Sistema General de Pensiones, cancillería, Colombia nos une, [en línea], 2016, marzo 2016, disponible en: http://www.redescolombia.org/ejes/sistema-deservicios-para-colombianos/seguridad-social-colombianos-exterior/sistemageneral-de-pensiones.

2. Ministerio de trabajo, todos por un nuevo país, [en línea], 2016, marzo y abril de 2016, disponible en: www.mintrabajo.gov.co/pensiones.html

3. Régimen Legal de Bogotá D.C., Propiedad de la Secretaría General de la Alcaldía Mayor de Bogotá D.C., Decreto 1406 de 1999 Nivel Nacional, [en línea], Diario Oficial 43652 de agosto 2 de 1999, abril 2016, disponible en http://www.alcaldiabogota.gov.co/sisjur/normas/Norma1.jsp?i=13585

4. Régimen Legal de Bogotá D.C., Propiedad de la Secretaría General de la Alcaldía Mayor de Bogotá D.C., LEY 1562 DE 2012 Nivel Nacional, El parágrafo $3^{\circ}$ del artículo 5, [en línea], Diario Oficial 48488 del 11 de julio de 2012, abril 2016, disponible

en http://www.alcaldiabogota.gov.co/sisjur/normas/Norma1.jsp?i=48365

5. Régimen Legal de Bogotá D.C., Propiedad de la Secretaría General de la Alcaldía Mayor de Bogotá D.C., DECRETO 19 DE 2012 Nivel Nacional, artículo 142, [en línea], Diario Oficial 48308 del 10 de enero de 2012, abril 2016, disponible en http://www.alcaldiabogota.gov.co/sisjur/normas/Norma1.jsp?i=45322

6. Administradora del fondo de pensiones, Colpensiones, Colombia, medicina laboral, [en línea], 2016, mayo 2016, disponible en https://www.colpensiones.gov.co/Default.aspx

7. Administradora del fondo de pensiones, Colpensiones, Manual de medicina laboral, [en línea], Última Actualización 17/02/2015, mayo 2016, disponible en https://colpensiones.gov.co/publicaciones/es-CO/132/Medicina_Laboral.

8. López Carlos, El estudio de tiempos y movimientos, [en línea], marzo 11 del 2001, julio 2016, disponible en http://www.gestiopolis.com/el-estudio-de-tiemposy-movimientos/ 
9. Luis Fernando Pinilla, Estudio de tiempos y movimientos, la medición de la productividad, [en línea], julio de 2016, disponible en http://www.metalactual.com/revista/33/administracion_medicion.pdf

10. ASALUD Ltda Asesorias y servicios en salud, auditoria médica integral, [en línea], marzo 2016, disponible en http://www.asaludltda.com/index.php

11. Dr Hector Parra, Enfoque Ocupacional en la Red.Educación Permanente en Ergonomia, Seguridad y Salud, enfoque ocupacional, [en línea], 26 de marzo 2013, julio 2016, disponible en http://www.enfoqueocupacional.com/2013/03/medicina-del-trabajo-conceptooms.html

12. Ministerio de trabajo, todos por un nuevo país, definición de incapacidad, [en línea], 2016, julio 2016, disponible en: http://www.mintrabajo.gov.co/preguntasfrecuentes/incapacidad.html

13. Corporación Universitaria Remington, PROCESOS ADMINISTRATIVOS Y ADMINISTRACIÓN POR LIDERAZGO, [en línea], 2011, julio 2016, disponible en https://gustavoadolfocarrascal.wikispaces.com/file/view/Procesos+Administrativo s+R.pdf

14. Las bases de la administración según Henri Fayol, Gestiopilis, [en línea], 2016, julio 2016, disponible en http://www.gestiopolis.com/las-bases-de-laadministracion-segun-henri-fayol/

15. Taylor y Fayol, Administración científica, [en línea], julio 2016, disponible en http://webcache.googleusercontent.com/search?q=cache:2snbRYD6H6kJ:www.fi ng.edu.uy/ mayr/Taylor_Fayol.doc+\&cd=2\&hl=es\&ct=clnk\&gl=co

16. Fayol, Teoría Clásica De La Administración, [en línea], julio 2016, disponible en http://www.aulafacil.com/cursos/l19660/empresa/administracion/administracionde-empresas/teoria-clasica-de-la-administracion-fayol

17. Programa de las Naciones Unidas para el Desarrollo, MANUAL DE PLANIFICACIÓN, SEGUIMIENTO Y EVALUACIÓN DE LOS RESULTADOS DE DESARROLLO, [en línea], 2009, julio 2016, disponible en http://web.undp.org/evaluation/evaluations/handbook/spanish/documents/manual _completo.pdf 
18. Roman Urribarri Valbuena, evaluación de la eficiencia y eficacia del proceso productivo de fábrica de bolsas plásticas, [en línea], 2006, julio 2016, disponible en http://bibadm.ucla.edu.ve/edocs_baducla/tesis/P945.pdf.

19. Tribunal De Cuentas Europeo CEAD, Manual De Auditoria De Gestión, [en línea], 2015, julio 2016, disponible en http://www.eca.europa.eu/Lists/ECADocuments/PERF_AUDIT_MANUAL/PERF_ AUDIT_MANUAL_ES.PDF

20. Universidad Politécnica de Nicaragua, Sede Estelí, II UNIDAD: EL AUDITOR ADMINISTRATIVO, [en línea], 2010, julio 2016, disponible en https://jalfaroman.files.wordpress.com/2010/08/el-auditor-administrativo.pdf 


\section{ANEXOS}

\section{Anexo 1: Formato De Entrega De Documentos (FED)}

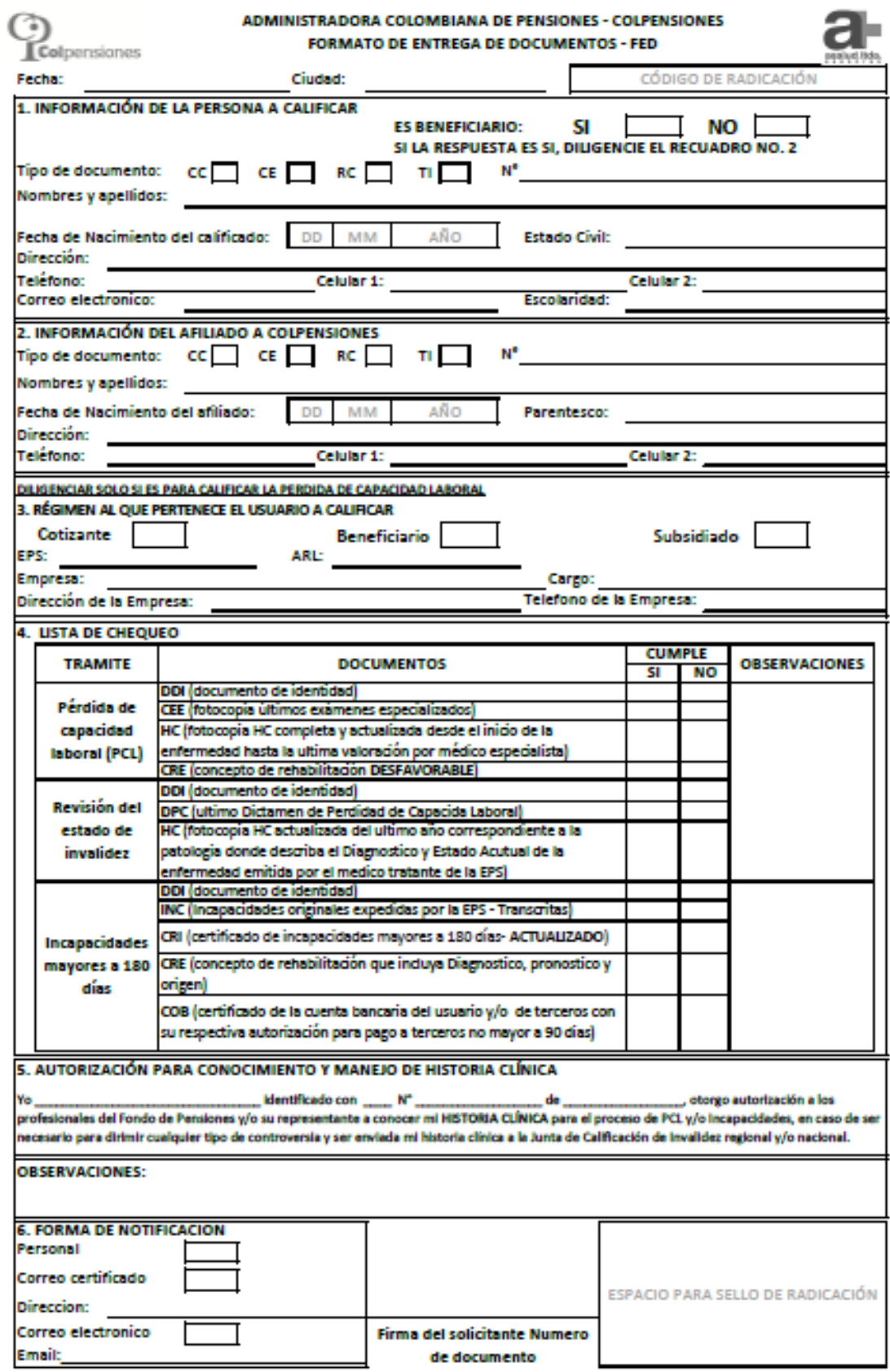

